News

\title{
Liberating children from a pattern of lies
}

\author{
Volume 2 Issue 2 - 2015
}

\section{Parents write: what advice do you have for parents with children who lie? our children have become far too proficient in this habit and we worry where this will lead them}

Children who habitually lie to their parents and other people leave a trail of doubt and distrust in their lives. Relationships suffer the greatest toll while the damage to their reputation, achievement levels, and self-esteem are also placed in jeopardy. Parents become ardent interrogators and friends look with wary suspicion upon the child's statements. The longer this self-defeating pattern persists the greater the likelihood that adulthood will be littered with betrayal and deceit. Parents may unwittingly make the problem worse by coming down too hard on the deceitful child. Rather than do so, consider the following coaching tips.

\section{Approach your child with caring concern rather than antagonistic accusation. children who lie will not lay down their defensive deceit under a barrage of angry confrontations \\ They must feel safe to accept they have a serious problem with dishonesty. This means that parents must not explode with rage when the child admits to having told a lie. Consider this response: "I'm relieved to hear you admit the truth but still very concerned that this problem with dishonesty continues. Are you willing to have a serious conversation about what might be fueling these patterns?"}

\section{Recognize the child lies to themselves about the source of the problem}

Don't expect any revelations from the child since they are often lacking insight into their behavior. One of the ways the problem perpetuates itself is through the use of rationalization, whereby the child justifies their behavior because of the feared consequences of telling the truth. Suggest to them that this view is a self-serving shell that keeps it going but doesn't explain how it started in the first place.

\section{Be prepared to offer specific sources of the problem}

The child may be more receptive if parents suggest that they have become trapped within a pattern that distorts or hides the truth. Explain how many paths lead people to this pattern and that stopping

\author{
Steven Richfield \\ Clinical Psychologist, Philadelphia, USA \\ Correspondence: Steven Richfield, Clinical Psychologist, \\ Philadelphia, USA, Tel 6I0-238-4450, \\ Email director@parentcoachcards.com \\ Received: January 17, 2014 | Published: January 19, 2015
}

it requires finding the reasons it started. "Sometimes kids start lying because they want to impress others. Other times the pattern begins because they don't want to ever be wrong or because they are feeling jealous or angry about certain things in their life," is one way to pursue this discussion. If they do open up, listen intently and without judgment.

\section{Empathize with their shame and suggest specific strategies to combat the problem}

"You must feel really bad about this at times, but I have good news: you can outgrow it," may help them be receptive to your ideas. Suggest the two of you sit down and write a "List of Lies" as a cathartic cleansing of the problem. This is a numbered account of all the times they can remember lying. Encourage them to practice telling a truthful account of a difficult situation where they failed to deal well with a challenge. See if they can bring this up with another trusted adult as way of clearing the path for greater truth in their life.

\section{Acknowledgments}

None.

\section{Conflicts of interest}

Author declares there are no conflicts of interest.

\section{Funding}

None. 